\title{
Metabolic compromise in women with PCOS: earlier than expected
}

\author{
(D) Maria Perez Lana ${ }^{2}$ \\ (iD) Sandra Demayo ${ }^{1,2}$ \\ (iD) Lorena Giannone 1,2 $^{12}$ \\ (iD) Manuel Nolting ${ }^{2}$ \\ (iD) Estela D'isa $a^{3}$ \\ (iD) Valeria Servetti $i^{1,2}$ \\ (iD) Guadalupe Rolo² \\ Guillermo Gutierrez $z^{2,3}$ \\ Mariana Jarlip ${ }^{2}$
}

1. Departament of Gynecology Argerich. Hospital. Buenos Aires, Argentina. 2. Argentinian Society of Gynecological and Reproductive Endocrinology, Buenos Aires, Argentina. 3. Departament of Diagnosis Central Laboratory Argerich. Hospital, Buenos Aires, Argentina.

http://dx.doi.org/10.1590/1806-9282.66.9.1225

\section{SUMMARY}

Polycystic ovary syndrome (PCOS) is an endocrinopathy with unknown pathophysiology among women of reproductive age. Several studies have been conducted to determine the prevalence of metabolic syndrome (MetS) among PCOS patients. Recent studies have reported varied prevalence of metabolic syndrome (MetS) in women with PCOS. The aim of this study is to determine if women with PCOS are at a higher risk of MetS or some degree of metabolic compromise.

METHODS: This is an observational study. A total of 96 women diagnosed with PCOS (according to the Rotterdam consensus criteria) were included. Variables of diagnostic criteria for MetS according to the ATP III were analyzed at the first consultation. Data analysis was performed using Epi Info TM 7.2.2.16.

RESULTS: We assessed the prevalence of obesity, blood pressure, glucose intolerance, and dyslipidemia in 96 women with PCOS and an average age of 28 (17-39) years. Forty percent of the women had BMI <25 kg/m2; 85.4\% had blood pressure $<730 / 85 \mathrm{~mm} \mathrm{Hg;} 22.9 \%$ had HDL cholesterol $>50 \mathrm{mg} / \mathrm{dl}, 57.3 \%$ had triglycerides $<750 \mathrm{mg} / \mathrm{dl}, 63.5 \%$ had fasting glucose $<100 \mathrm{mg} / \mathrm{dl}$. According to the ATP III criteria for MetS, $8.33 \%$ met none of the criteria, $19.79 \%$ met one criterion, $15.63 \%$ two criteria, $41.67 \% 3$ criteria, $13.54 \% 4$ criteria, and $1.04 \%$ met the 5 criteria.

CONCLUSION: Considering the high prevalence of MetS or altered metabolic components in PCOS patients at the moment of the diagnosis, its regular screening is necessary to reduce the mortality and morbidity rates in these women.

KEYWORDS: Polycystic ovary síndrome. Metabolic syndrome. Obesity. Glucose intolerance. Dyslipidemias.

\section{INTRODUCTION}

Polycystic ovary syndrome (PCOS) is an endocrinopathy with unknown pathophysiology and a prevalence of $6-10 \%$ in reproductive-age women ${ }^{1}$. Although
PCOS can manifest at any stage of reproductive life, it often develops during adolescence. Polycystic ovary syndrome is typified by both reproductive and 
hyperandrogenic features that include oligo-amenorrhoea, impaired fertility, hirsutism, acne, and androgenic hair loss. Polycystic ovary syndrome often also presents with hyperandrogenaemia.

Polycystic ovary syndrome is an important example of a metabolic disorder associated with insulin resistance, its manifestations include cardiometabolic risks and the effects of which are greatly amplified by obesity. Accordingly, PCOS is associated with heightened risk for the development of T2D, impaired glucose tolerance, dyslipidemia, non-alcoholic fatty liver disease, and obstructive sleep apnoea ${ }^{2}$.

Several studies have been conducted to determine the prevalence of metabolic syndrome (MetS) among PCOS patients. Recent studies have reported a varied prevalence of metabolic syndrome (MetS) in women with $\mathrm{PCOS}^{3,4}$. The aim of this study is to determine if the women with PCOS are at a higher risk of MetS or some degree of metabolic compromise at the moment of diagnosis.

\section{METHODS}

\section{Study design}

This cross-sectional study was conducted at the Gynecological and Reproduction Section, Argerich Hospital, Argentina, from October 2010 to October 2018. Women diagnosed with PCOS during this period were consecutively enrolled.

\section{Participants}

Patients with PCOS were identified based on the revised 2003 Rotterdam consensus criteria, in which two out of three of the following conditions must be met: (1) the presence of oligo- and/or anovulation, (2) clinical and/or biochemical signs of hyperandrogenism, and (3) polycystic ovaries on ultrasonography. Other causes of hyperandrogenism, such as congenital adrenal hyperplasia, androgen-secreting neoplasms, and Cushing syndrome, were excluded. Women who had hypothyroidism or hyperprolactinemia, were on oral contraceptive medication within 3 months prior to the time of enrolment, were on insulin sensitizers, or who had established diabetes (type 1 or type 2 ) were also excluded from the study.

\section{Measurements}

Anthropometry and blood pressure

The height and weight of each subject were measured. The body mass index (BMI) was calculated by dividing the body weight in kilograms by the square of the height in meters. The BMI values were categorised as underweight $\left(<18.5 \mathrm{~kg} / \mathrm{m}^{2}\right)$, normal $(18.5$ to $\left.24.9 \mathrm{~kg} / \mathrm{m}^{2}\right)$, overweight $\left(25.0\right.$ to $\left.29.9 \mathrm{~kg} / \mathrm{m}^{2}\right)$, and obese $\left(\geq 30 \mathrm{~kg} / \mathrm{m}^{2}\right)$. Systolic blood pressure (SBP) and diastolic blood pressure (DBP) were measured in the sitting position after a 5-minute rest.

\section{Biochemical assays}

Venous blood samples were collected in the morning after an overnight fast on the second or third day of the patient's spontaneous or progesterone-induced menstrual cycle. Fasting glucose and lipid panel analyses including total cholesterol, triglycerides (TGs), HDL-C, and low-density lipoprotein cholesterol (LDL-C) were performed using Cobas 6000 C501 Roche.

\section{Definition of variables and outcomes}

We defined MS using the NHLBI/AHA ATP III guidelines. A diagnosis of MS was made when $\geq 3$ of the following were present: (1) $\mathrm{WC} \geq 80 \mathrm{~cm}$, (2) TG $\geq$ $150 \mathrm{mg} / \mathrm{ml}$, (3) HDL-C $<50 \mathrm{mg} / \mathrm{ml}$, (4) blood pressure (BP) $\geq 130 / 85 \mathrm{~mm} \mathrm{Hg}$, and (5) fasting glucose $\geq 100$ $\mathrm{mg} / \mathrm{ml}^{5}$.

\section{Statistical analysis}

Descriptive statistics were used to determine the characteristics of the study population.

Data analysis was performed using Epi Info ${ }^{\mathrm{TM}}$ 7.2.2.16.

\section{RESULTS}

We assessed the prevalence of obesity, blood pressure, glucose intolerance, and dyslipidemia in 96 women with PCOS, aged 28 (17-39) years. Forty percent of women had BMI $<25 \mathrm{~kg} / \mathrm{m} 2 ; 85.4 \%$ had blood pressure $<130 / 85 \mathrm{~mm} \mathrm{Hg} ; 22.9 \%$ had HDL cholesterol $>50 \mathrm{mg} / \mathrm{dl}, 57.3 \%$ had triglycerides $<150 \mathrm{mg} / \mathrm{dl}, 63.5 \%$ had fasting glucose $<100 \mathrm{mg} / \mathrm{dl}$. Table 1

TABLE 1. METABOLIC LABORATORY RESULTS

\begin{tabular}{l|l|l} 
Variable & Normal results (\%) & Abnormal results (\%) \\
\hline BMI & 40 & $60 /$ Obesity: 48 \\
\hline Blood pressure & 85.4 & 14.6 \\
\hline HDL c & 22.9 & 77.1 \\
\hline Triglycerides & 57,3 & 42.7 \\
\hline Fasting glucose & 63.5 & $27.1 /$ DBT2: 9.4 \\
\hline
\end{tabular}


At the time of the PCOS diagnosis, $44 \%$ of the patients met the diagnostic criteria for MetS.

According to the ATP III criteria for MetS, 8.33\% met none of the criteria, $19.79 \%$ met one criterion, $15.63 \%$ met two criteria, $41.67 \% 3$ criteria, $13.54 \% 4$ criteria, and $1.04 \%$ met the 5 criteria. Figure 1

FIGURE 1. DIAGNOSTIC CRITERIA OF ATP III IN PCOS WOMEN

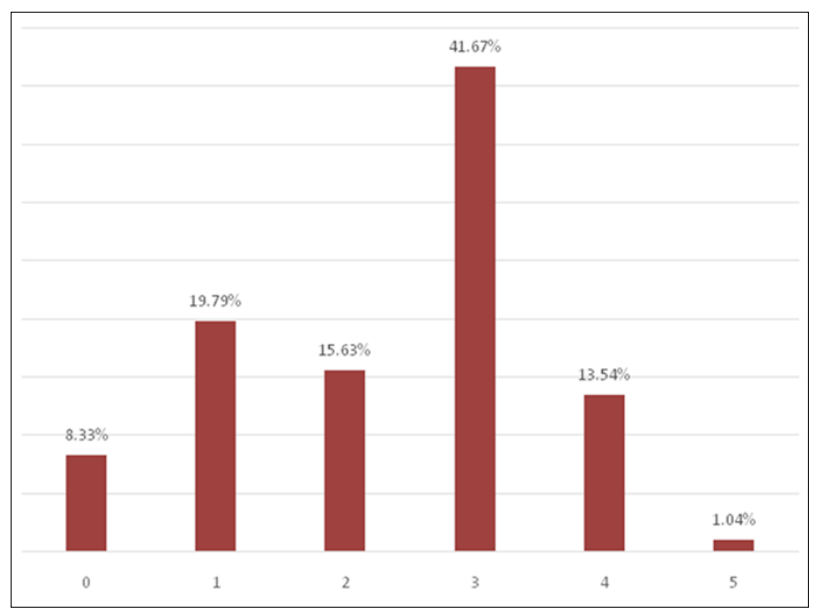

Analysis of results according to altered variable Obesity: 83\% presented low HDL; $46 \%$ had hypertriglyceridemia; $51 \%$ had altered fasting glucose.

Altered fasting glucose: $94.28 \%$ of the patients presented low HDL, $45.71 \%$ had altered triglycerides; 51.42 had BMI greater or equal than 30.

Altered blood pressure: $85.71 \%$ of the patients presented low HDL, 50\% hypertriglycerides; $37.7 \%$ altered fasting glucose; $64.28 \%$ had BMI greater or equal than 30.

\section{DISCUSSION}

Women with PCOS present a number of systemic symptoms in addition to those related to the reproductive system. In fact, PCOS is associated with significant metabolic consequences ${ }^{2}$.

MS is a complex of interrelated risk factors for CVD and diabetes. The clinical definition of the MS has been developed over the past two decades with the purpose of identifying individuals at increased risk of these diseases to put in place preventive measures that can reduce this risk ${ }^{5}$.

In our current population, only $8.33 \%$ of the patients did not show any metabolic alteration, and 43.75\% some MetS. These alterations influence the development of metabolic disorders.
In women who are genetically predisposed to the development of PCOS, weight gain and obesity often result in clinical and biochemical manifestations. Accordingly, there are close links between obesity and PCOS ${ }^{6}$. The majority of women with PCOS in this study (60\%) are either overweight (12\%) or obese (48\%). Weight-gain and obesity worsen insulin resistance and features of metabolic syndrome. Weight-gain and obesity in women with PCOS also promote worsening insulin resistance, and both metabolic dysfunction and the characteristic reproductive and hyperandrogenic features of this condition ${ }^{6}$.

The most common lipid abnormalities among women with PCOS are elevated levels of triglycerides (TG), low-density lipoprotein cholesterol (LDL-C), very-low-density lipoprotein cholesterol (VLDL-C), and low high-density lipoprotein cholesterol (HDL-C) levels ${ }^{4}$. Moreover, obese and thin women with PCOS often present an atherogenic lipid profile, together with other biochemical cardiovascular risk factors.

In our patients, the parameter more affected was HDL-c $(77 \%$ had values $<50 \mathrm{mg} / \mathrm{ml})$, perhaps as a result of obesity and glycemic status. Only $22 \%$ of the patients in our population had HDL-C in the normal range. Considering that $40 \%$ of PCOS women had normal BMI, our results show that the decrease in HDL-c occurs independently of body weight.

In line with the present findings, previous cross-sectional studies including adolescent and young reproductive-aged women with PCOS have reported significantly higher blood pressure levels in them compared with controls. In our analysis, overweight/ obesity was associated with hypertension, outlining the important role of excess weight as a determinant of hypertension in women with PCOS.

Hypertension develops in women with PCOS from hyperaldosteronism via the activation of the renin-angiotensin system. Previous studies have shown that women with PCOS appear to have higher aldosterone levels than age- and BMI-matched controls, though within normal limits ${ }^{4}$. Additionally, insulin resistance-related compensatory hyperinsulinemia has been implicated in the occurrence of hypertension in women with PCOS.

As mentioned, and given the high prevalence of some component of metabolic syndrome at the time of diagnosis of PCOS, we consider that they should be taken into account as an early complication of the syndrome. 
The management of women with PCOS should focus on specific symptom manifestations and be tailored to the individual. According to the recently published international PCOS guidelines, global CVD risk should be routinely assessed in women with $\mathrm{PCOS}^{2-4,7}$.

\section{CONCLUSIONS:}

PCOS is a chronic disease with health implications across the lifespan.

The increased metabolic risk can be found at the time of diagnosis of PCOS and not as a longterm complication.

Patients with PCOS should be fully evaluated to determine baseline metabolic parameters. Women with PCOS may require more regular screening at diagnosis for such risks as well as effective and targeted early lifestyle advice.

Considering the high prevalence of MetS or altered metabolic components in PCOS patients, its early diagnosis is necessary to reduce the mortality and morbidity rates in these women.

\section{RESUMO}

A síndrome dos ovários policísticos (SOP) é uma endocrinopatia com fisiopatologia desconhecida em mulheres em idade reprodutiva. Vários estudos foram realizados para determinar a prevalência da síndrome metabólica (SM) em pacientes com SOP. Estudos recentes relataram prevalência variada de síndrome metabólica (SM) em mulheres com SOP. O objetivo deste estudo é determinar se as mulheres com SOP apresentam maior risco de SM ou algum grau de comprometimento metabólico.

MÉTODOS: Estudo de desenho observacional. Foram incluídas 96 mulheres diagnosticadas com SOP (de acordo com os critérios de consenso de Roterdã). Variáveis de critérios de diagnóstico para SM de acordo com o ATP III foram analisadas na primeira consulta. A análise dos dados foi realizada usando o Epi Info ${ }^{T M}$ 7.2.2.16.

RESULTADOS: Avaliamos prevalência de obesidade, pressão arterial, intolerância à glicose e dislipidemia em 96 mulheres com SOP, com idade de 28 (17-39) anos. Quarenta por cento das mulheres tinham IMC $<25$ kg/m2; 85,4\% tinham pressão arterial < 130/85 mm Hg; $22,9 \%$ tinham colesterol HDL >50 mg/dl, 57,3\% tinham triglicerídeos $<150 \mathrm{mg} / \mathrm{dl}$, 63,5\% tinham glicemia de jejum < $100 \mathrm{mg} / \mathrm{dl}$. Segundo os critérios do ATP III para SM, 8,33\% não possuíam critérios, 19,79\% possuíam um critério, 15,63\% possuíam dois critérios, 41,67\% possuíam três critérios, $13,54 \%$ possuíam quatro critérios, 1,05\% possuía os cinco critérios.

CONCLUSÃo: Considerando a alta prevalência de SM ou algum componente metabólico alterado em pacientes com SOP no momento do diagnóstico, sua triagem regular é necessária para reduzir as taxas de mortalidade e morbidade nessas mulheres.

PALAVRAS-CHAVE: Síndrome do ovário policístico. Síndrome metabólica. Obesidade. Intolerância à glucose. Dislipidemias.

\section{REFERENCES}

1. Tavares A, Rêgo Barros RC. The prevalence of metabolic syndrome in the different phenotypes of polycystic ovarian syndrome. Rev Bras Ginecol Obstet. 2019;41(1):37-43

2. Delitala AP, Capobianco G, Delitala G, Cherchi PL, Dessole S. Polycystic ovary syndrome, adipose tissue and metabolic syndrome. Arch Gynecol Obstet. 2017;296(3):405-19.

3. Anagnostis P, Tarlatzis BC, Kauffman RP. Polycystic ovarian syndrome (PCOS): long-term metabolic consequences. Metabolism. 2018;86:33-43.

4. Morgante G, Massaro MG, Di Sabatino A, Cappelli V, De Leo V. Therapeutic approach for metabolic disorders and infertility in women with PCOS. Gynecol Endocrinol. 2018;34(1):4-9.

5. Sam S. Adiposity and metabolic dysfunction in polycystic ovary syndrome. Horm Mol Biol Clin Investig. 2015;21(2):107-16
6. Goodman NF, Cobin RH, Futterweit W, Glueck IS, Legro RS, Carmina E; American Association of Clinical Endocrinologists (AACE); American College of Endocrinology (ACE); Androgen Excess and PCOS Society (AES). American Association of Clinical Endocrinologists, American College of Endocrinology, and Androgen Excess and PCOS Society disease state clinical review: guide to the best practices in the evaluation and treatment of polycystic ovary syndrome--part 1. Endocr Pract. 2015;21(11):1291-300.

7. Alberti KG, Eckel RH, Grundy SM, Zimmet PZ, Cleeman II, Donato KA, et al. Harmonizing the metabolic syndrome: a joint interim statement of the International Diabetes Federation Task Force on Epidemiology and Prevention; National Heart, Lung, and Blood Institute; American Heart Association; World Heart Federation; International Atherosclerosis Society; and International Association for the Study of Obesity. Circulation. 2009;120(16):1640-5. 